e-ISSN: 1981-4755

DOI: $10.5935 / 1981-4755.20170011$

\title{
As Des-Reterritorializações de Cuiabá Na Obra de Silva Freire
}

\author{
The de-reterritorializations of Cuiabá in the works of Silva Freire
}

\author{
Vinicius Carvalho Pereira* \\ *Universidade Federal de Mato Grosso, UFMT, Cuiabá - MT, 78060-900, e-mail: \\ viniciuscarpe@gmail.com \\ Mark Sabine** \\ **University of Nottingham, UoN, Nottingham NG7 2RD, Reino Unido, e-mail: \\ mark.sabine@nottingham.ac.uk
}

RESUMO: O objetivo do presente artigo $^{1}$ é analisar como Cuiabá e a cuiabania integram temática e retoricamente textos em prosa e verso de Silva Freire, construindo uma espacialidade que é tanto simbólica quanto política, o que implica entender como o poeta cartografou não só o espaço da cidade, mas também, em alguma medida, o direito de pertença à mesma. Assim, em lugar de ler o regional como um valor em si ou como uma instância transcendida com vistas a um estético absoluto, a perspectiva que aqui se adota é a de que Silva Freire constrói uma dinâmica desterritorializadora e reterritorializadora (DELEUZE; GUATTARI, 1997; HAESBAERT, 2011) da cidade em seus escritos. Desse modo, Freire mapeia movediços limites entre os distintos grupos que passam a ocupar o espaço da cidade ao longo do século $\mathrm{XX}$, mas também invisibiliza as comunidades que habitavam o território local antes da colonização. Ao recriar poeticamente uma Cuiabá, o autor assume distintas posições discursivas nas intrincadas negociações identitárias que se dão na cidade nesse período, redefinindo, a cada novo texto, a quem de direito são a manga e o caju que a terra dá.

Palavras-chave: Silva Freire; regionalismo; Cuiabá; des-reterritorialização.

ABSTRACT: The objective of this article is to analyze how Cuiabá and "Cuiabaness" feature thematically and rhetorically Silva Freire's writings in prose and poetry, building a spatiality that is both symbolic and political. To this end, it explores how the poet mapped not only his city, but also, to some extent, the right to belong to it. Rather than reading the regional as a value in itself, or as an instance to be transcended with a view to an aesthetic absoluteness, we herein adopt the perspective that Silva Freire creates a de-territorializing and re-territorializing (DELEUZE; GUATTARI, 1997; HAESBAERT, 2011) dynamic of Cuiabá in his writings. Thus, Freire maps the shifting limits between different groups who occupied the city throughout the 20th century, but also effaces the communities who

1 A pesquisa foi apoiada por recursos da Fundação de Amparo à Pesquisa do Estado de Mato Grosso FAPEMAT.

Volume 18

Número 40 


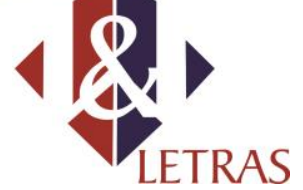

e-ISSN: 1981-4755

DOI: $10.5935 / 1981-4755.20170011$

inhabited that territory before its colonization. In recreating Cuiabá poetically, the author takes up different discursive stances in the intricate identity negotiations that happened in the city over that period, thereby redefining, in every new text, to whom belong the mango and the cashew that its land famously yields.

KEYWORDS: Silva Freire; regionalism; Cuiabá; de-/re-territorialization.

"O povo que chupa o caju, a manga, o cambucá e a jabuticaba, pode falar uma língua com igual pronúncia e o mesmo espírito do povo que sorve o figo, a pera, o damasco e a nêspera?" (José de Alencar)

\section{INTRODUÇÃO}

A frase que faz as vezes de epígrafe a este artigo, redigida por José de Alencar no prefácio de Sonhos d'Ouro, ainda no século XIX, bem poderia ser de autoria de um escritor mato-grossense do século XX: Silva Freire. Esse poeta, ainda que partícipe das vanguardas das décadas de 60 e 70, majoritariamente voltadas para uma poesia visual de ares internacionalistas, adotou em seus textos em prosa e verso uma dicção e uma temática fortemente regionalistas, garantindo-lhes cor, cheiro e gosto de caju e de manga - frutas, aliás, que compõem a mesa cuiabana; cadenciam o ciclo da natureza, segundo a cultura local $^{2}$; e figuram na obra de Freire, localizando sinestesicamente a memória afetiva frente a Cuiabá:

Bairro da minha infância. Casa de meus pais, Randolpho Rodrigues Freire e Joanna Euphrosina da Silva Freire. Galinha choca no quintal!, (...) Gaiola de periquitos setembrinos roendo mangapiquí... O ronrosnar do cavalo Café, que papai adornava de carícias e broto picado de bocaiuveira para afinação do sangue e rebrilho da pelagem, faiscando no sol. (...) As fôrmas de fazer rapadura, como escadinhas dos gostos satisfeitos nos sabores de leite de côco, goiaba e casca-de-caju, desarrumada no gavetão, ainda cheirando canela e erva-doce. (FREIRE, 1991a, p.123, grifos nossos)

Para além da coincidência nas frutas mencionadas por ambos os escritores, nota-se um expediente retórico comum a esses fragmentos, ainda que em contextos distintos em termos de tempo (séculos XIX e XX) e espaço (Ceará e Mato Grosso): a referência a territórios através de elementos da natureza assimilados pela cultura. Com tal metáfora,

\footnotetext{
2 De acordo com a cultura cuiabana tradicional, as pancadas de chuva que ocorrem no final de setembro (temporariamente amainando o período da seca anual no cerrado) garantem a floração do cajueiro e da mangueira e o posterior desenvolvimento de suas frutas.
}

Volume 18

Número 40 
Alencar, em meio ao projeto romântico de criação de uma identidade nacional, opõe uma língua e um espírito brasileiros a seus correspondentes lusitanos. Já Freire, diante das mudanças por que passa sua cidade na segunda metade do século XX, reafirma valores e imagens caros à noção de cuiabania então propalada. Assim, em ambos os textos, o caju e a manga designam um eu (ou um nós) em oposição a um outro, construindo comunidades que escondem sua discursividade ideológica - como a de todo território - sob a naturalidade e a organicidade que a imagem das frutas evoca.

A polarização entre supostos universal e local (o outro indiferenciado e o eu particularizado, construídos sempre da perspectiva de quem fala) é uma das linhas de força pelas quais a historiografia literária na América Latina se escreve. Tais operadores de leitura foram (e muitas vezes ainda o são) empregados no continente, sobretudo na crítica de obras românticas e modernas, enfatizando o processo de gradativa diferenciação e independência das jovens nações em relação à tradição literária das (ex-)metrópoles coloniais (RAMA, 2001). No caso do Brasil, o "local" ganha, nas obras lidas segundo essa perspectiva, diferentes dimensões: ora designa o território nacional, afirmando-se frente ao império português, como na célebre "Canção do exílio", de Gonçalves Dias, ou nos romances indianistas de José de Alencar; ora particulariza uma região dentro do país, opondo-se a um suposto "nacional uniforme" (por paradoxal que seja a expressão), ou ao cânone urbano (sobretudo das regiões Sul e Sudeste) do sistema literário brasileiro. Destaquem-se, nesse caso, os romances de 30, de autores como José Lins do Rego, Graciliano Ramos e Rachel de Queiroz, em que o interior do Nordeste brasileiro é particularizado e tematizado em contraposição a uma suposta homogeneidade dos centros urbanos nacionais.

Antonio Candido (1989) leu as produções românticas e as modernas de cunho regionalista segundo duas posturas distintas que dominavam, respectivamente, as cenas intelectuais do século XIX e da primeira metade do século XX: naquela, o otimismo do "país novo", que compensaria o atraso material com o exotismo da natureza e do homem local; nesta, a consciência do subdesenvolvimento, com consequências mais agudas à época no sertão nordestino. Na mudança de paradigma entre tais perspectivas, Candido destaca um amadurecimento desmistificador da literatura nacional e uma progressiva mudança rumo a uma postura política mais ativa e engajada. No entanto, segundo a perspectiva de Silviano Santiago, a discussão proposta por Candido não rompe completamente com uma lógica binária eurocêntrica que lê toda literatura nacional como uma "síntese de tendências Volume 18

Número 40 
particularistas e universalistas" (SANTIAGO, 1996, p. 32).

Ainda dentro do movimento dialético de forças e fluxos identitários que compõem o regionalismo, parte significativa da crítica literária brasileira empreendeu e empreende uma leitura deveras desistoricizada desse fenômeno, tornando-se refém de jargões como "as belezas da terra", a "transcendência do local para chegar ao universal", "o universal no regional" etc. Referindo-se à limitação dessa perspectiva crítica no estudo da literatura matogrossense, Barbosa (2011, p.125) advoga uma abordagem político-econômica do regionalismo na formação do sistema literário em Mato Grosso. Para tanto, o pesquisador afirma a impossibilidade de qualquer neutralidade no tratamento do regionalismo, uma vez que “a expressão 'regional' toma feições positivas ou negativas, enaltecedoras ou redutoras, ou perde o valor, de acordo com a situação em que é usada e, claro, de acordo com quem a usa". Complementando tal raciocínio, lembra-nos ainda que,

quando se fala de universal nos textos de Mato Grosso, subjaz aí uma ideia um pouco vaga de essência do ser humano, de valores iguais comuns a qualquer sociedade, quando o que ocorre é que, no campo da cultura, como em qualquer outro, o valor é dado sempre a partir de uma posição de poder que o determina. Fala-se de universal em oposição ao regionalismo como elemento redutor, representado por símbolos ligados à identificação do local, de seus aspectos físicos e tipos humanos (BARBOSA, 2011, p.125).

No caso da crítica mato-grossense, especialmente a realizada sobre textos do século $\mathrm{XX}$, a dialética entre regional e supostamente universal muitas vezes descambou para uma hierarquização entre tais polos, utilizando-se como vara de medida para os juízos críticos uma leitura do local como via de acesso a universais estéticos, conforme se analisará mais detidamente na próxima seção do presente artigo. Negligencia-se, nesse sentido, em que medida a formação do campo e do sistema literário local em torno do regionalismo se articula com projetos políticos e culturais para o estado de Mato Grosso (LEITE, 2015) e, mais tarde, para a capital Cuiabá.

Além disso, cabe aqui destacar que, na análise de como esses territórios se constroem na prosa e na poesia de Mato Grosso, é rara a discussão do marco temporal a partir do qual se discute a construção de uma cultura e de uma literatura local. Desse modo, frequentemente são invisibilizadas as sociedades pré-coloniais e inadequadamente se adota uma perspectiva de cultura mato-grossense produzida ab nihilo a partir da chegada dos bandeirantes. 
Mais ainda, muitas vezes passa ao largo da crítica literária quem define o regional e a região na literatura mato-grossense, e como, quando e por quê o faz. Atribui-se, assim, uma indevida naturalidade ao que é ideológico, desde a demarcação do território físico aos recortes dos grupos culturais e sociais que convivem (ou não) no território.

O objetivo da discussão que aqui se enseja é, nesse contexto, analisar como Cuiabá e a cuiabania ${ }^{3}$ integram temática e retoricamente textos em prosa e verso de Silva Freire, construindo uma espacialidade que é tanto simbólica quanto política, o que implica entender como o poeta cartografou não só o espaço da cidade, mas também, em alguma medida, o direito de pertença à mesma. Assim, em lugar de ler o regional como um valor em si ou como uma instância transcendida com vistas a um estético absoluto, a perspectiva que aqui se adota é a de que Silva Freire constrói uma dinâmica desterritorializadora e reterritorializadora (DELEUZE; GUATTARI, 1997; HAESBAERT, 2011) da cidade em seus escritos, mapeando movediços limites entre os distintos grupos que passam a ocupar o território local ao longo dos diferentes fluxos migratórios no século XX. Ao recriar poeticamente uma Cuiabá, o autor assume distintas posições discursivas nas intrincadas negociações identitárias que se dão na cidade nesse período, redefinindo, a cada novo texto, a quem de direito são a manga e o caju que a terra dá.

\section{MAPEANDO OS TERRITÓRIOS CRÍTICO E ACADÊMICO}

Em texto crítico sobre a poética de Freire publicado na $4^{\mathrm{a}}$ edição de Águas de Visitação (2002), Célio da Cunha, professor da UnB e amigo de longa data do poeta, assim encerra seu comentário analítico:

Dissemos no início que uma das virtudes de Freire é saber captar a essência desta terra e gente. É preciso dizer contudo que a poesia de Silva Freire não está circunscrita a determinado lugar. Ele parte do regional em busca do universal, parece até que seguindo os conselhos de Julien Brenda, que num diálogo com André Gide argumenta que quanto mais regional for o escritor, tanto mais universal será. (DA CUNHA apud FREIRE, 2002, p.160)

A análise acima se coaduna com uma tendência predominante na crítica à literatura

\footnotetext{
${ }^{3}$ Substantivo usado para designar a cultura e a identidade cuiabana, bem como movimentos de resgate e preservação da memória em Cuiabá.

Volume 18

Número 40
} 
mato-grossense, identificada por Barbosa (2011), e também à poesia de Silva Freire. A ideia de uma "essência desta terra e gente", a qual desconsidera que toda cultura é apenas um ponto em uma rede espaciotemporal de hibridizações, bem como as profundas mudanças sociopolíticas e ambientais sofridas nos últimos quinhentos anos pelo que hoje se chama Cuiabá, abunda também nos trabalhos acadêmicos sobre o poeta e nas historiografias literárias de Mato Grosso, ainda que a(s) identidade(s) cuiabana(s) não figurem de maneira inalterada ao longo de toda a obra freireana.

Em recente tese de doutorado sobre a obra de Silva Freire, um discurso semelhante se articula em torno de um regionalismo que tem seu valor chancelado pela academia na medida em que se abre para o universal.

Silva Freire estabelece uma relação intensa em que, de um lado acontece a ruptura com o passado e a criação do novo, na medida em que propõe uma estética sem restrições, tomando como ponto de partida o projeto concretista verbivocovisual e, por outro, sua arte vai em busca da defesa de valores nacionais-culturais e regionais.

Alguns críticos encaram essa relação como problemática, pois, ao entrar no universo das culturas regionais, o autor poderia fragilizarse e, consequentemente, tornar sua poesia puramente bairrista. Constatamos, contudo, que Freire se utiliza das relações culturais e regionais sem as fragilizar, alçando-se rumo ao universal. (MAGALHÃES E., 2014, p.50, grifos nossos)

A fim de dar conta da tensão entre forças mais internacionalistas (das vanguardas poético-visuais) e mais localistas (da tradição cuiabana), ambas presentes na poesia de Silva Freire, a hipótese de leitura do pesquisador Epaminondas Magalhães é a do regional "alçando-se rumo ao universal". O recurso à primeira pessoa do plural na última frase do excerto acima sugere um ato de fala em que o sujeito da enunciação se engaja no enunciado de forma menos distante do que a praticada nas frases anteriores, como se fizesse uma aposta interpretativa dos dados colhidos em sua pesquisa, mas para salvaguardar Freire de "alguns críticos" do bairrismo, aos quais faz alusão no início do parágrafo.

O regional é assim validado nos referenciais estéticos da academia apenas ao ser lido (e, em alguma medida "defendido") segundo a linguagem do cânone ${ }^{4}$ (termo mais ideologicamente carregado para designar o que uma crítica anterior aos estudos culturais

\footnotetext{
${ }^{4}$ Haja vista a extensão do artigo, não se pode aqui expandir a discussão sobre o conceito de cânone. Apenas indicamos, portanto, que a problematização de cânone ora aludida é baseada na discussão de Gorak (1991).

Volume 18

Número 40
} 
chamaria de "universal" - o "universal" que a tradição literária europeia ocidental cunhou como forma supostamente não marcada de expressão poética).

Mediando com um pouco mais de cautela as relações entre regional e universal, Hilda Magalhães, ao usar o termo "universal" para situar a obra de Silva Freire entre o regional e o pretensamente global, problematiza a noção de universalidade contra a qual o regional é entendido, destacando a relatividade e a arbitrariedade dessas definições:

Eé nesse universo, explorado em suas particularidades mais íntimas, que a verve de Silva Freire encontra espaço para o experimentalismo, atrelado, de modo mais estreito possível, às coisas regionais. Talvez, nesse sentido, seja possível compreender as palavras de João Antônio Neto, para quem Silva Freire não é universal, a menos que se entenda por universal "ir até às últimas raízes de determinada intenção do autor, mas não no sentido de extensão geográfica ou aceitação unânime". (MAGALHÃES H., 2001, p.166, grifos nossos)

Tomando como mote as "últimas raízes de determinada intenção do autor", que marcaria uma busca universal, segundo João Antônio Neto e Hilda Magalhães, pretende-se neste artigo ler a obra de Silva Freire não como um discurso em que o regional seja caminho para o universal, e sim como um território discursivo cujas raízes (termo ambíguo entre os campos semânticos da origem e da natureza) são objeto permanente de negociação, conforme a configuração do sistema e do campo literário em sua época. Nessa proposta exegética, mais do que um elogio à terra, a escrita freireana seria uma constante redemarcação de terra, em que se circunscrevem os grupos sociais que têm diferentes direitos à identidade construída em torno de Cuiabá.

Para entender a negociação de sentidos envolvida na cartografia do território ${ }^{5}$ cuiabano na obra freireana, parte-se aqui das operações de desterritorialização e reterritorialização que o poeta opera ao cartografar simbolicamente sua região e o direito de pertença a ela. A esse respeito, Deleuze e Guattari entendiam os agenciamentos humanos e, por conseguinte, as identidades - como efeitos moventes de territorialização. Nessa perspectiva, o território não é um dado a priori, que pudesse simplesmente ser descrito; tratase de um construto cultural a partir de uma convergência muito seletiva e até exclusória de

\footnotetext{
${ }^{5}$ Entende-se aqui "território" não só como uma porção de terra, mas como um construto discursivo que se constrói na confluência dos referentes concretos de um espaço, das identidades dos povos que o habita, na distribuição desigual de acesso aos bens e recursos materiais e da administração política (HAESBAERT, 2011). Volume 18
}

Número 40 
fatores sociais, políticos, históricos e econômicos. Silva Freire não representa, pois, Cuiabá em seus textos; ele a constrói em seus escritos, reestabelecendo, a cada novo ato enunciativo, seus moventes limites e fronteiras simbólicas.

O território é, sob tal perspectiva, sempre um produto parcial e temporário de um processo de territorialização, que é fluido, rítmico, expressivo, como a própria poesia:

O território não é primeiro em relação à marca qualitativa, é a marca que faz o território. As funções num território não são primeiras; elas supõem, antes de tudo, uma expressividade que faz território. É de fato nesse sentido que o território, e as funções que aí se exercem, são produtos da territorialização. A territorialização é o ato do ritmo tornado expressivo, ou dos componentes de meios tornados qualitativos. (DELEUZE; GUATTARI, 1997, p. 122, grifos nossos)

As cadeias significantes delineiam contornos semiótica e politicamente instáveis, territórios de que os sujeitos entram e/ou saem, ou em que são condenados a uma imobilidade interior e/ou exterior. Os agenciamentos discursivos dizem sempre quem pertence ou não a determinado território, a determinada cultura, a determinada linguagem que compõe o território: "Todo agenciamento é, em primeiro lugar, territorial. A primeira regra concreta dos agenciamentos é descobrir a territorialidade que envolvem, pois sempre há alguma (...)" (DELEUZE; GUATTARI, 1997, p. 218).

Nesse sentido, Haesbaert (2011) nos lembra que toda territorialização é um processo duplo, pois envolve uma desterritorialização e uma reterritorialização; trata-se, então, nas palavras do autor, de des-reterritorialização. Nesse movimento ambivalente, a desconstrução de um território implica sempre a construção de um outro. Por sua vez, a construção do território, ao incluir alguns, necessariamente exclui, ou inclui precariamente (HAESBAERT, 2011), outros. Não há território universal, assim como não pode haver "regional universal", o que invalida os chavões de parte significativa da crítica literária regionalista. Se um território, ou uma região, é sempre produto parcial de uma delimitação a ser refeita a cada enunciação, em uma ininterrupta dialética de inclusão e exclusão (LEITE, 2015), a próxima seção deste artigo discute como tais limites são perpetuamente reconfigurados na poética freireana e por que contingências históricas, na segunda metade do século XX, tal cartografia sobressai na produção desse escritor. 


\section{POÉTICAS DE "CHAPA E CRUZ"6}

Sob o lema de "Integrar para não entregar", porções significativas do Centro-Oeste e do Norte brasileiro foram incorporadas a um imaginário nacionalista pela propaganda estatal do período da ditadura militar no Brasil, nas décadas de 60 a 80 (OLIVEIRA, 1988). O que era até então entendido nos grandes centros urbanos apenas como selva, sertão ou grotão, passou a ser reterritorializado pela comunicação governamental também como "Brasil”, o que justificaria, no plano simbólico, uma série de ações políticas e econômicas com vistas à urbanização e à ocupação da região da Amazônia, do Cerrado e de espaços circunvizinhos.

Mato Grosso foi um dos estados brasileiros que mais aceleradamente sofreu alterações durante a política desenvolvimentista militar, o que incluiu a divisão do estado em Mato Grosso e Mato Grosso do Sul; a construção de grandes estradas, como a BR-163; a fundação da Universidade Federal de Mato Grosso; a expansão da fronteira agrícola no norte do estado; e a reurbanização de Cuiabá. Todos esses processos acarretaram novos fluxos migratórios, de pessoas oriundas de distintas regiões do país e com diferentes propósitos, acelerando um processo de ocupação do território mato-grossense que data do período précolonial, intensifica-se com as bandeiras e potencializa-se no integracionismo militarista.

Tais eventos na segunda metade do século XX levaram a uma ressignificação dos espaços rurais, urbanos e naturais de Mato Grosso, tanto aos olhos dos que vinham de fora quanto dos que já habitavam a região. No caso específico da capital do estado, as elites intelectuais locais frequentemente adotaram uma posição conservadora, que visava a reafirmar seus valores e, por consequência, frequentemente desterritorializar discursivamente aqueles que traziam novos signos culturais para a cidade. Em alguns de seus escritos, Silva Freire, membro da Academia Mato-Grossense de Letras a partir de 1985, assume explicitamente essa posição mais conservadora, traçando contornos do que seja a cuiabania e justificando a necessidade de preservá-la:

(...) entendemos que sua [de Cuiabá] tradição religiosa, ao longo do tempo imemorial, fincou raízes tão profundas no comportamento existencial da comunidade, ao ponto mesmo de se situar hoje como a mais expressiva manifestação do processo cultural popular da cuiabania;

- apesar das profundas transformações sócio-econômicas da Região, o culto popular ao Milagroso São Benedito, continua a se fortalecer

\footnotetext{
${ }^{6}$ Também grafada como "tchapa e cruz", para indicação da pronúncia africada da primeira consoante, esta expressão idiomática é utilizada em Cuiabá para designar os nascidos e falecidos em Cuiabá, em op

Volume 18
}

Número 40 
na consciência coletiva do Povo, assumindo proporções mais do que religiosas, para colocar-se mesmo como uma das principais bases de sustentação da auto-defesa da tenacidade e existência cuiabanas;

- é diante desse quadro que as novas gerações haverão de refletir para envolverem-se e se comprometerem na continuidade da luta para que esses e outros valores permaneçam não só intactos como fortalecidos ante a agressão das novas formas de civilização tecnocrata (FREIRE, 1986, p.216, grifos do autor).

Nesse excerto, retirado de texto sobre uma tradicional comemoração na cidade, a festa de São Benedito, Freire se refere à importância da preservação da tradição cultural, tomandoa como metonímia do sentimento de cuiabania. Tal substantivo, por si só, já encerra significados bastante relevantes, sobretudo ao ser negritado pelo escritor: a cuiabania não é um traço de Cuiabá, mas sim do cuiabano. Trata-se, pois de uma marca identitária que transpõe, do nível político (um município) ao humano, uma marca sígnica que se opõe ao que é exógeno.

Reforçando tal efeito de sentido no texto freireano, associam-se à noção de “cuiabania" termos associados à terra e à fixidez, como "raízes" e "base". No discurso de Freire, essas referências ao território conduzem a uma dicotomia entre defensores ("autodefesa da tenacidade e existência cuiabanas") e agressores ("as novas formas de civilização tecnocrata"). Interessante é notar que, nos termos do autor, tal "civilização tecnocrata" não é descrita como um processo de mudança inerente a Cuiabá, ou mesmo originário de necessidades ou demandas locais; trata-se de ameaça que vem de fora, mediante política desenvolvimentista federal, contra a qual ele convoca as novas gerações cuiabanas para a luta, sob a bandeira do regionalismo.

Se, no excerto acima, a oposição entre o dentro e o fora estava associada às forças então entendidas como conservadoras e transformadoras de Cuiabá, definindo claramente os territórios a que pertencem os sujeitos que nessa dialética se engajam, no poema a seguir, retirado de )presença na audiência do tempo(, semelhante limite entre o dentro e o fora se replica não mais só na urbanização da cidade, mas também na sua poetização.

- tentando explicar o que é do sentir:

- mas onde está a poesia de sua cidade, homem!?

- lá..., veja, ainda pendendo do galho da encantada laranjeira cuiabana; a gente querendo despencá-las com o chuço-da-taquara-do-gosto e..., de repente, as frutas reverdecem nos cachos, endurecendo seus talos...; paciência, recomeçar o namoro com as frutas!

Volume 18

Número 40 
e-ISSN: 1981-4755

DOI: $10.5935 / 1981-4755.20170011$

- só isso?

- alí, também, nos beirais-dos-telhados-coloniais-fazendo-

beicinhos prô levantar-dos-olhos-dos-paus-rodados...

(FREIRE, 1991b, p.413)

Nesse poema em prosa, redigido como fragmento de uma entrevista, o poeta responde de onde vem "a poesia de sua cidade". Note-se que a pergunta do entrevistador lança mão do ambíguo sintagma "de sua cidade", o qual poderia designar uma poesia sobre a cidade; feita na cidade; ou, por metonímia, feita por alguém nascido na cidade. A mesma ambiguidade se nota nas definiç̧ões de literatura mato-grossense, de Mato Grosso, ou feita em Mato Grosso, as quais acabam por delimitar, do ponto de vista crítico ou historiográfico, diferentes participantes do sistema literário dessa região segundo seus eixos estruturantes: a região e o regionalismo.

De maneira algo análoga ao caju e à manga de Alencar, mencionados na epígrafe a este artigo, a poesia de Cuiabá é também nesse poema-entrevista metaforizada por uma fruta: a laranja. Não se trata, porém, de qualquer laranja; é a que brota da "encantada laranjeira cuiabana", sendo aqui o adjetivo toponímico designador não de uma árvore ordinária, mas especificador de uma árvore especial. Tal operação discursiva territorializa no reino do mítico a poesia local, além de estabelecer um forte vínculo hipertextual entre o texto de Silva Freire e um dos mais célebres e ufanistas sonetos de Dom Aquino Corrêa, intitulado "A laranjeira cuiabana" (1940). Tal recurso ao dialogismo entre Silva Freire e D. Aquino acaba por ressaltar, do ponto de vista crítico, uma relação de continuidade temática entre o escritor do século XX e o fundador do sistema literário de Mato Grosso, em detrimento das rupturas formais que a poética de vanguarda freireana frequentemente enseja.

Ainda no poema-entrevista, imagens comuns à descrição do lírico, como sua associação ao orgânico e a paciência do poeta ante o tempo do próprio poema, são ressignificadas no espaço cuiabano. Essas tópicas se inscrevem no território local na medida em que as laranjas-poesia são cutucadas "com o chuço-da-taquara-do-gosto". A escolha de itens lexicais característicos do dialeto cuiabano para designar o instrumento com que se tocariam as frutas poéticas é uma operação retórica nos níveis fonológico (soando o linguajar do povo no texto) e semântico (marcando que só tange a laranja quem dispõe de um traço de cuiabania, seja a língua, a identidade, ou o chuço de taquara).

Essa marcação da cuiabanidade como pré-requisito para realizar uma "poesia de sua cidade" é reforçada pela clara oposição que o poema cria entre "a gente" (grupo em que o eu Volume 18

Número 40 
lírico se inscreve, como capaz de operar o chuço) e os "paus-rodados", ou migrantes, para quem as laranjas apenas fazem beicinho, jocosamente ressaltando sua inacessibilidade aos que vêm de fora. Estes não conhecem a linguagem da laranjeira cuiabana e não sabem esperar seu tempo, estando à margem, da "poesia de sua cidade". Trata-se, portanto, de território que não lhes pertence, senão na condição de espectadores.

$\mathrm{O}$ jogo entre pertença e não pertença, interioridade e exterioridade, torna-se ainda mais evidente se considerarmos o título do livro em que o poema está publicado: )presença na audiência do tempo(. A cartografia identitária de Cuiabá é uma tônica desse poema, o qual tem em seu título índices das primeiras coordenadas a partir das quais um território é definido: o tempo e o espaço. Porém, em vez de um simples binarismo entre o dentro e o fora, o jogo gráfico no título do livro, virando os parênteses para fora, faz do exterior um interior, e vice-versa, processo de hibridização que é comum quando diferentes culturas negociam sentidos em um mesmo território, o que é abordado de maneira menos dicotômica em outros textos da obra de Freire.

O borrar de fronteiras entre o dentro e o fora, ou o "aqui" e o "lá", o eu e o outro, estabelecendo limites menos precisos para a cuiabania, figura, por exemplo, em um texto do autor em que as mudanças desterritorializadoras de Cuiabá não são mais atribuídas exclusivamente a um agente exógeno, mas sim a uma dialética mais complexa, que se constitui inicialmente por uma série de negações:

- Não, Cuiabá, não são as crianças que lhe sangram de agulhas envenenadas a veia jugular da vida...

[...]

- Não são elas que estão garroteando seus santos de festas, suas lendas e mitos.

$[\ldots]$

- Quem ordenha suas tetas maternais, para traí-la depois, não são as crianças. Elas só sabem amar sua bondade ferida.

- Não são as crianças que debicam de sua história-orgulho nacional [...]

- Não são as crianças que se esquecem de seus valores permanentes. Elas se alimentam das raízes da raça.

- Não são as crianças que enriquecem a curto prazo e a qualquer preço, à custa de seu empobrecimento...

- Quem está descarnando seu patrimônio espiritual?

- Quem quer apagar a memória de seu Povo?

\footnotetext{
${ }^{7}$ Expressão com que se designam em Cuiabá os migrantes, em alusão ao graveto ou galho que cai em um rio, é levado pela correnteza e, em algum ponto, engancha na margem e ali se fixa.

Volume 18
}

Número 40 
e-ISSN: 1981-4755

DOI: $10.5935 / 1981-4755.20170011$

- Quem deforma a sua imagem histórica?

- Quem dilapida sua herança?

- Quem camufla a trambicagem?

- Não são as crianças que borram a imundície da vida em suas paredes seculares. As crianças, suas crianças, Cuiabá, sabem pinturar de alegria a cidade-útero-materno.

- Não, redigo: as crianças são o poema inconsútil da vida, ninhando a peraltice no andor do arco-íris cuiabano. (FREIRE, 1986, p.223224)

Nesses excertos do poema em prosa "Canto-murmúrio para minha cidade", o mote não é exatamente uma descrição de Cuiabá, e sim uma narração das mudanças pelas quais vai passando a cidade, interlocutor a quem se dirige o eu-lírico.

O longo poema em prosa estabelece claramente uma repulsa às mudanças por que passa Cuiabá na segunda metade do século XX. Tal sentimento é expresso por meio de verbos que carregam conotações de agressividade, pilhagem e destruição, como "sangrar", "garrotear", "trair", “descarnar”, “deformar”, “dilapidar” etc. Nesse sentido, ressalte-se que Cuiabá retorna em quase todas as sentenças do poema através dos pronomes possessivos "seu", "sua" e suas flexões, indicando uma relação íntima entre o território atacado e o aspecto da tradição e da cultura local que é pilhado, tal como "seus santos de festa, suas lendas e seus mitos", "sua história-orgulho nacional", "seus valores permanentes", "seu patrimônio espiritual" etc. Nessa enumeração que o poema estabelece, a maioria dos substantivos designam elementos supostamente caros à comunidade local, referindo-se metonimicamente à cuiabania como um todo, em um processo que essencializa e homogeneíza a cultura sob o discurso da tradição.

No entanto, ao mesmo tempo em que enuncia a ocorrência desses assaltos contra a cidade, o eu lírico adota como expediente retórico uma série de lítotes, negando serem as crianças as agressoras da tradição; afinal, estas são "o poema inconsútil da vida" e mantêm uma relação íntima - ou mesmo visceral - com a "cidade-útero-materno".

Ao intercalar construções como "não são as crianças" e o pronome interrogativo “quem”, o eu-lírico vai estilisticamente construindo uma crescente atmosfera de mistério, em que não se descobre até o final do texto quais são os agentes da violência que, no fundo, não se opera contra a cidade, e sim contra a tradição que funda esse território no imaginário do poeta.

$[\ldots]$

- Não, não são as crianças que estão rasgando o tecido cultural da

Volume 18

Número 40 
cidade!

- As crianças são o futuro-interior da comunidade, e vão pedir contas à história.

- Oh, "seu" Delegado!, "seu" Fiscal, "seu" Secretário, sr. Prefeito, Guarda Civil, Chefes, Chefes, tantos chefes!, - a posse da cidade não é posse da função!

- Não, Cuiabá, não são as crianças:

- são os trogloditas da cultura, daqui e de lá;

- são os mastodontes das bibliotecas, de lá e daqui;

- são os brutamontes da história, daqui e de lá;

- são os crocodilos das escolas, de lá e daqui;

- são os tisanuros da espécie, daqui e de lá;

- são os rinocerontes dos jardins, de lá e daqui;

- são os eunucóides mentais, daqui e de lá;

- são os tricerátopes sobrevivos, de lá e daqui;

- são os atanajuras da política, daqui e de lá;

- são os mentecaptos da cidade, de lá e daqui, os que estão traindo a Terra de Rondon, Dom Aquino Corrêa e Rubens de Mendonça. (FREIRE, 1986, p.225, grifos do autor)

Nos últimos versos do poema acima transcritos, o eu-lírico finalmente enuncia que, em lugar das crianças (tradicional símbolo poético da inocência), a ameaça se dá por "trogloditas da cultura", "mastodontes das bibliotecas", "brutamontes da história", “crocodilos das escolas", "tisanuros da espécie", "rinocerontes dos jardins", "eunucóides mentais", "tricerátopes sobrevivos", "atanajuras da política", "mentecaptos da cidade". Tal enumeração, se analisada mais de perto em termos estilísticos, permite identificar alguns dispositivos retóricos por meio dos quais Freire desenha a arena onde se dão a desterritorialização de Cuiabá pelos agressores e sua reterritorialização na resposta poética do eu lírico.

Em primeiro lugar, as forças representadas por esses agentes não estão dicotomicamente associadas a uma transformação exógena, em oposição a uma interioridade tradicional, como se notara no texto sobre a festa de São Benedito. Em "Canto-murmúrio para minha cidade", cada categoria de agressores é descrita ora como "daqui e de lá", ora como "de lá e daqui”, num quiasma que reposiciona, visual e fonicamente, cada um daqueles que investem contra a tradição. Isso implica dizer que a ameaça não vem só de fora, mas também de dentro, não estando necessariamente associada à origem geográfica dos sujeitos, mas sim a outros fatores e interesses.

A escolha lexical com que se nomeiam esses agressores é também significativa, uma vez que a maior parte dos termos é do campo semântico da animalidade ("mastodontes", Volume 18

Número 40 
"crocodilos", "atanajuras" etc.) ou da estupidez ("trogloditas" e "mentecaptos"), o que estabelece aparentemente uma oposição entre cultura (cuiabana) e natureza/desrazão (das bestas perigosas daqui e de lá/de lá e daqui). No entanto, essa divisão binária se desfaz quando se nota, paradoxalmente, que tais bestas não são de carga ou da selva, mas sim "da cultura", "das bibliotecas", "das escolas" etc.

Neste poema, a nomeação dos agressores se dá por meio de elaborados substantivos polissílabos - construções morfofonológicas relativamente raras na língua portuguesa e geralmente associadas a uma linguagem mais erudita. Tais vocábulos, junto com as locuções adjetivas que designam territórios da cultura oficial, sugerem que o que ameaça a tradição cuiabana, mais do que uma força que vem de fora - dos "paus rodados" -, seria uma força que vem da cultura que se supõe superior por estar associada a grupos de elite (do "seu Delegado", "seu Fiscal", "seu Secretário" etc.), não necessariamente aos migrantes ou aos "locais". A acirrada disputa identitária, inerente à constituição e reafirmação de todo território - fluxo ininterrupto que é, na perspectiva de Deleuze e Guattari (1997) -, ganha, então, uma dimensão socioeconômica, e não simplesmente geopolítica entre os que já estão e os que vêm.

Tal complexificação das identidades que se negociam ao longo das mudanças por que passa Cuiabá na segunda metade do século XX está diretamente associada, na escrita de Freire, ao desenvolvimento de um projeto de política cultural em parceria com Wlademir Dias-Pino:

Então, nós fizemos um trato, eu e Freire. Como nós poderíamos trabalhar e lutar por uma identidade, uma identidade cuiabana. E aí nós fizemos um pacto. Então, se nós dois lutássemos na mesma direção eu vou repetir você e você vai me repetir. Então eu, eu, sugeri a seguinte coisa: você fica cuidando da sua obrigação social que é sua origem, defendendo a cuiabania, tornando ela, ela, clara, de uma clareza, que possa ser reformada a hora que quiser, etc., e desmanchando os esconderijos e as armadilhas políticas que se armaram e eu vou trabalhar no cuiabano novo. Numa possível vanguarda cuiabana. Então, como eu sou mais teórico que você eu fico incumbido dessa parte da teoria e você fica incumbido na prática, no uso dessa prática. (DIAS-PINO apud LEITE, 2015, p.150).

Diretamente engajados no fortalecimento de uma cena cultural e literária cuiabana, Silva Freire e Wlademir Dias-Pino trabalharam juntos na elaboração de revistas e jornais em Mato Grosso, como O Arauto de Juvenília, Ganga, Sarã e Saci. Tais atividades, junto com a 
organização de exposições e o desenvolvimento de novos movimentos literários, como o Intensivismo e o Poema//Processo, fazem parte do projeto de política cultural acima descrito por Dias-Pino. Interessante, nesse contexto, é pensar como a cultura cuiabana é entendida explicitamente nessa fala como um processo de mediações e fluxos, mais do que como uma identidade fixa que se oporia a um suposto universal. Em lugar de uma "essência cuiabana", ou de uma "tradição cuiabana" em luta contra a modernização ou a homogeneização, o que o projeto cultural acima descrito sugere é uma atuação em duas frentes: uma "defendendo a cuiabania", a ser liderada por Freire; e outra, com Wlademir Dias-Pino, a "trabalhar no cuiabano novo". Juntas, essas frentes formam uma cuiabania processual, e não estanque, “(...) que possa ser reformada a hora que quiser, (...) desmanchando os esconderijos e as armadilhas políticas que se armaram".

Considerando ainda que Wlademir Dias-Pino é um autor carioca que migra para o Mato Grosso ainda jovem e vive, depois, entre as duas cidades, sua condição de "paurodado", colaborando com Freire, é aqui descrita como elemento estruturante da estratégia traçada no projeto cultural. Ao mato-grossense Silva Freire, caberia cuidar "da sua obrigação social que é sua origem, defendendo a cuiabania", ao passo que o carioca Dias-Pino agiria "numa possível vanguarda cuiabana" - que, em alguma medida, pode ser relacionada ao "futuro-interior da comunidade", representado pela novidade que prometiam as crianças em "Canto murmúrio para minha cidade". O dentro e o fora, o mato-grossense que passa parte de sua vida no Rio, e o carioca que passa parte de sua vida em Cuiabá, acabam por estabelecer aí uma divisão de trabalhos que não segue uma fronteira absoluta, e sim permanentemente renegociada, que des-reterritorializa suas identidades na agência da política cultural.

Tal abordagem mais flexível da cuiabania, proposta no projeto cultural de Wlademir Dias-Pino e Silva Freire, resta, por fim, patente no poema abaixo, de Silva Freire, estruturado também como entrevista acerca da identidade de Cuiabá:

- aspado de aprender:

- por que você define Cuiabá como cidade rurbana?

- porque ela viveu a experiência-histórica-do-tempo.

- repita, não entendi.

- veja, a experiência-histórica-do-tempo filtra a cultura, enquanto a experiência-geográfica-do-espaço gera a atitude cultural meramente sertaneja. No caso de Cuiabá, tendo nascido rente ao topográfico, rasgando-a-geografia-dosertão-em-veias (sua faina garimpeira), assumiu o compromisso da experiência-histórica-do-tempo. (...) 
(FREIRE, 1991b, p.395)

Chama a atenção, logo à primeira leitura, o neologismo "rurbana", produto de hibridização linguística que revela uma interpenetração não só lexical, mas também identitária, entre rural e urbano. Cuiabá deixa aí de ser uma cidade com identidade monolítica - ou uma "unicidade" - para se tornar, progressivamente, mais e mais rurbana, no que preserva algo de suas origens ao mesmo tempo em que se altera conforme o processo acelerado de urbanização.

A partir dessa escolha vocabular, observa-se que, neste poema, as transformações de Cuiabá já não são mais tratadas tão peremptoriamente como agressão ou pilhagem, e sim como um processo de hibridização de culturas, espaços e tempos, que a cidade "assumiu [como] compromisso". Uma recusa à identidade homogeneizada sob o rótulo do regional se delineia já no uso do advérbio "meramente" em "a experiência-geográfica-do-espaço gera a atitude cultural meramente sertaneja”. Note-se aí que o eu-lírico reforça que sua cidade deve ser definida pela "experiência-histórica-do-tempo", que enseja a mudança histórica e "filtra a cultura" (e, portanto, paradoxalmente a transforma ao mesmo tempo em que a purifica), e não pela "experiência-geográfica-do-espaço", que atrelaria a cidade a um estereótipo do sertanejo. Isso não significa, porém, abrir mão da espacialidade inerente à construção de qualquer território: Cuiabá, no poema, é nascida "rente ao topográfico", o que influencia, mas não define categoricamente, sua identidade.

Por outro lado, se a construção "nascido rente ao topográfico, rasgando-a-geografiado-sertão-em-veias (sua faina garimpeira)" valoriza a "experiência-histórica-do-tempo", fálo a partir de um marco temporal que é, em si, também excludente, reterritorializando novamente grupos a quem pertenceria ou não o território. Afinal, se Cuiabá "nasce” em decorrência da mineração e do rasgar da "geografia-do-sertão-em-veias", a metáfora do nascimento sugere uma origem ab nihilo, postulando fora do território em questão - e mesmo do discurso poético - as comunidades que ocupavam aquele espaço antes da chegada de bandeirantes e garimpeiros.

\footnotetext{
${ }^{8}$ Referência ao ambíguo termo "unicidade", que designa o único, mas também uma "cidade una" em outro poema de Silva Freire, que alude a uma Cuiabá anterior aos fluxos migratórios das décadas de 60 a 80: "quase quando a cidade/ (antes da curra do progresso obsessivo)/ era unicidade... e se limitava/ às próprias cracas centenárias" (...). (FREIRE, 1991a, p.36).
}

Volume 18

Número 40 


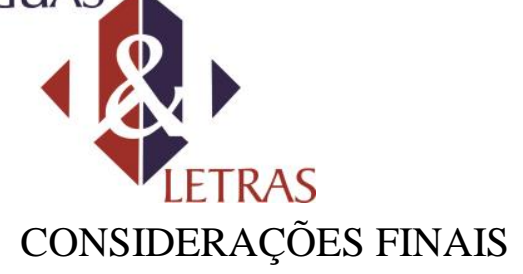

e-ISSN: 1981-4755

DOI: $10.5935 / 1981-4755.20170011$

Discutir o regional, seja na linguagem literária, seja na metalinguagem crítica, é sempre realizar cartografias, traçando, reforçando ou rasurando limites e fronteiras num mapa de traços geográficos, políticos, mas, sobretudo, identitários e culturais. Silva Freire, membro de uma comunidade que se identificava e muito ainda se identifica sob o signo da cuiabania, atendeu a diferentes chamados para assumir posições de protagonismo discursivo na cartografia de Cuiabá. Em cada uma delas, ora assumindo um discurso mais ligado à tradição, ora mais aberto à hibridização cultural com os migrantes da segunda metade do século XX mas quase nada com as sociedades pré-coloniais -, o autor replicou para o tratamento do regional a dialética entre conservadorismo e vanguarda que marca sua produção dentro do sistema literário de Mato Grosso.

Em seus textos, as transformações por que passou Cuiabá foram associadas tanto a ameaças externas quanto a devires internos, a depender do ato enunciativo em jogo. Por outro lado, muitas vezes a tênue linha que separa os de dentro e os de fora é negociada e reposicionada na escrita freireana, reinventando uma cuiabania a cada novo encontro cultural. De todo modo, o regional não é colocado pelo autor em contraponto ao universal, como parte da crítica afirma. A região é, em seus textos, arena de negociação identitária, em que as forças endógenas e exógenas ora convergem, ora divergem, a depender da conjuntura em que se dá a enunciação de Silva Freire.

Nesse sentido, mais uma vez torna-se pertinente revisitar a imagem do caju e da manga, com que se abriu a reflexão conduzida no presente artigo. Afinal, nem o cajueiro, árvore nativa do litoral brasileiro, nem a mangueira, nativa do Sudeste asiático, podem ser ditas plantas de fato cuiabanas, embora hoje constituam de forma quase simbiótica a cultura e a paisagem da cidade. Pertencer ou não à região se torna, nesse caso, uma questão de perspectiva ou recorte espacio-temporal, definidos por motivações históricas, políticas e econômicas. Enfim, levados ao cerrado por fluxos migratórios, o caju e a manga - de chapa e cruz, mas também paus-rodados - perpetraram transformações que passam pelo econômico, pelo biótico e pelo estético, dando novas cores, aromas e gostos que foram reterritorializados como emblemáticos da cuiabania - ela mesmo território em negociação permanente.

Volume 18

Número 40 


\section{REFERÊNCIAS}

BARBOSA, Everton Almeida. A tendência regionalista da crítica literária e a posição do intelectual em Mato Grosso. In: SANTOS, Luzia A. O. dos. Tópicos de leitura: literatura e contexto. Cuiabá: Edição da organizadora, 2011.

CANDIDO, Antonio. A educação pela noite \& outros ensaios. São Paulo: Ática, 1989.

CORRÊA, Dom Francisco de Aquino. Terra Natal - versos. Rio de Janeiro: Imprensa Nacional, 1940.

DELEUZE, Gilles; GUATTARI, Félix. Mil platôs: capitalismo e esquizofrenia. Vol. 4. São Paulo: Editora 34, 1997.

FREIRE, Silva. )na moldura da lembrança(. Cuiabá: UFMT, 1991 b. . ) presença na audiência do tempo(. Cuiabá: UFMT, $1991 \mathrm{a}$. . Águas de visitação. Cuiabá: Carlini \& Caniato, 2002. Silva Freire: social, criativo, didático - catálogo de exposição. Cuiabá: Imprensa Universitária, 1986.

GORAK, Jan. The Making of the Modern Canon: Genesis and Crisis of a Literary Idea. Londres: Athlone, 1991.

HAESBAERT, Rogério. O mito da desterritorialização: do "fim dos territórios" à multiterritorialidade. Rio de Janeiro: Bertrand Brasil, 2011.

LEITE, Mário Cezar Silva. Literatura, vanguardas e identidades: nas brenhas do regionalismo. Cuiabá: Carlini \& Caniato, 2015.

MAGALHÃES, Epaminondas de Matos. Por entre brenhas, picadas a foice, matas bravas: a produção poética em Mato Grosso no século XX e XXI. Tese de Doutorado. Programa de Pós-Graduação em Letras, da Universidade Católica do Rio Grande do Sul. São Paulo, 2014. MAGALHÃ̃ES, Hilda G. D. História da literatura de Mato Grosso: século XX. Cuiabá: Unicem, 2001.

OLIVEIRA, Ariovaldo Umbelino. Integrar para não entregar. Políticas públicas na Amazônia. Campinas: Papirus, 1988.

RAMA, Angel. Os processos de transculturação na narrativa latino-americana. AGUIAR, Flávio; VASCONCELOS, Sandra Guardini T.; RAMA, Angel (Org). Literatura e cultura na América Latina. São Paulo: Edusp, 2001.

SANTIAGO, Silviano. Atração do mundo (Políticas de identidade e de globalização na moderna cultura brasileira). Gragoatá. Niterói, vol.1, n.1, p. 31-54, 1996.

Data de recebimento: 31/08/2017

Data de aprovação: 31/08/2017 